\title{
SPATIAL DISTRIBUTION OF HEALTH LITERACY AMONG RURAL COMMUNITIES IN RANAU DISTRICT
}

\author{
Nadira Binti Masuari, Haryati Abdul Karim \\ University of Malaysia Sabah \\ nadira_masuari@yahoo.com
}

\begin{abstract}
Health literacy is a vital skill that everyone should have in order to find, understand and use communication and health information to improve their health. It is a crucial thing in public health which should be given attention especially in rural communities as the lack of literacy knowledge may the cause of poor health conditions. The aim of this study is to map the level of health literacy among rural communities in Ranau district. The objective of this study is to identify the distribution pattern of health literacy. Therefore, spatial analysis methods were applied to analysis data. The data were collected through questionnaires integrated into the Geographic Information System (GIS) database as an attributes data. Then, spatial analysis was conducted to identify the distribution of the health literacy. Subsequently, the study was able to visualize the geographical distributions of health literacy level data in a form of a map. The result shows that people who lived in rural areas with limited access to health information and lack of health facilities are more likely to have low health literacy compare to those lived in areas with unlimited access to health information and good health services. Hence, this study provides the data to the Public Health Department and Health Promotion division, so they could take necessary measures with reference to the high-risk areas. This information could effectively be used in communicating with, and as well as educating the public on awareness, prevention, and better healthcare to enhance the quality of life among communities, mainly in rural areas.
\end{abstract}

Keywords: GIS, Health literacy, rural community, spatial analysis

\section{Introduction}

The concept of health literacy which was introduced in the early 1970s has been widely used in public healthcare research since the last few years ago (Abdurrahman et al., 2017). Although the terms of health literacy has been 
rapidly evolved in South Europe, Asia and Australia (Sorensen et al., 2012; Kondilis et al., 2008), yet there are still very limited study on health literacy in Malaysia and most of literacy studies were only focused on specific diseases and demographic groups (Jasmin \& Siti, 2013). Health literacy (HL) is defined as a cognitive and social skills, which determine the motivation and the ability of individuals to obtain access, to understand and use information in ways, which promote and maintain good health (WHO, 1998, cited in Nutbeam et al., 2006). One of the main reasons why health literacy is crucial in public health because it has been proven that poor literacy skills lead to the low health status which it is not only occurs in developing countries but also in developed countries (Nutbeam, 2008). HL is becoming an important determinant of life expectancy and might also affect quality of life (Meng, et al., 2018). DeWalt et al., (2012) pointed out that along with a higher level of health literacy; there was a greater improvement in quality of life. Based on National Health and Morbidity Survey (NHMS) (2015) report shows that the prevalence of health literacy among Malaysians was at the lowest, which is $6.6 \%$. In terms of urban and rural areas in Malaysia, there was a huge difference between the rate of health literacy of urban and rural population. It was found that the prevalence of adequate health literacy among urban population was higher than rural population, which is $7.8 \%$ and $2.3 \%$ respectively. According to the Health Indicators report (2003-2010) prepared by the Ministry of Health shows that people in Sabah are more commonly exposed to infectious diseases such as Tuberculosis, Leprosy and Hepatitis B. For example, Sabah recorded as the highest diffusion cases of Hepatitis B (TB) in Malaysia, which is 5106 cases in 2017 (Utusan Borneo, 2018). Apart from that, statistics released by the Ministry of Health showed an increase in non-communicable diseases, where the increase in cases for hypertensive disease was $43 \%$, diabetes increased by $88 \%$ and obesity by $25 \%$ in 2012 compared to 2002 (Jasmin \& Siti, 2016). Such situation indicates that the low level of health literacy might lead to low health status. This suggests that understanding and basic knowledge of self-health care are important to maintain good health which may affect the quality of life. Geographic Information System (GIS) has been commonly utilized to visualize geographically-referenced data in a map format not only in research projects but also in practice (Takashi \& Scott, 2012). GIS is a computer system for capturing, managing, integrating, manipulating, analyzing and displaying data which is spatially referenced to the Earth (Mcdonnell \& Kemp, 1995). As the capability of GIS has been improved over the past few years in accordance with the era of Industry Revolution 4.0 in which the advancements of computer technology is seen as significant things, spatial analysis is now getting recognition as one of the most powerful analysis 
tools which can be applied in various field of studies. In research context, GIS has been widely used in epidemiology and public health research. GIS can be used for disease surveillance purpose (Cromley, 2003); detection of high risk areas or populations (Cossman et al., 2003; Rushton et al., 2008); as well as policy and public health intervention program planning (Holt et al., 2008; Pickle \& Su, 2002; Sui \& Holt, 2008). Most of the previous research using GIS and health-related were only focused on spatial distribution of disease, development of preventative and control measures of disease, accessibility to healthcare facilities, and so on. However, there are very limited studies on health literacy using GIS technology, particularly in Malaysia. Hence, this study aims to map the level of HL among communities in rural areas so that Health Department, especially Promotion Health Division could take effective approaches for intervention programs at riskareas which shows the population has high prevalence of limited HL.

\section{Literature review}

The concept of 'Health Literacy' has been typically defines as "the degree to which individuals have the capacity to obtain, process and understand basic health information and services needed to make appropriate health decisions (US Institute of Medicine, 2004 cited in Nutbeam, 2008). Berkman et al., (2010) argued that most scholars defined 'health literacy' as individual-level construct and often concentrated on a person's capability to process and understand health information. However, to assume that one is able to make informed decisions about their health independent of other external factors is problematic. As Parker (2000) pointed out many patients are facing great difficulty in communicating with their healthcare providers about their conditions because they lacked the basic knowledge of health vocabulary. Among others, Sorensen et al., (2012) after reviewing 17 definitions of health literacy, have produced an integrated conceptual model of health literacy, which goes beyond individual literate ability to include situational determinants and societal and environmental determinants as well. The model focuses on four types of competencies, which is accessing, understanding, appraising and applying health-related information. However, Nutbeam $(2000 ; 2008)$ stated that the concept of health literacy is not only limited to accessing, understanding, appraising and applying health information, but it should involve the dimension of communication skills of individual in interacting with health experts. Therefore, a health literacy model has produced which consist of three dimensions and each of them have different meaning of health literacy. The three dimensions are functional health literacy, interactive health literacy and critical health literacy. 
A mapping health literacy study has been conducted by Nicole et al., (2009) in Missouri State. They were using National Assessment of Adult Literacy (NAAL) in measuring the HL, and data were retrieved from public use micro data (PUMAs) and census tract. They were using hotspots analysis to identify the locations of people with low HL. The result shows that people living in northeast St Louis and the Western part of Kansas City had the lowest average HL scores, with one area in East St. Louis having the lowest health literacy in the state. While, most areas of central Missouri and the bootheel region have populations $60 \%$ to $70 \%$ has 'above basic' HL. However, the result was not really accurately generalized because it shows that only rural areas were highlighted as 'below basic' HL, while in central areas were shown as 'above basic' HL. NAAL tools is not suitable for measuring HL in a large areas as there were no classification such as an urban, suburban and rural as they might have different lifestyle, eating habits, education level and income. So, in suggestion, a comparation of HL level study among population in urban and rural areas can be done by using the suitable tools of measuring HL for both areas.

\section{Method and study area}

Ranau was chosen as a study area. It is located at the West Coast Division of Sabah. One of the reasons why Ranau was chosen as the study area is because of high rate of poverty in most rural areas. According to UPE Sabah reports, poverty rate in Ranau is approximately 38.2\% (Sabah Economic Planning Unit, 2004). Poverty is crucial because it is also linked to access to education which will attribute to basic functional literacy of read and write in an individual. Another reason is that most of rural community is still engaged in economic activities which concentrated on agriculture and natural resources. Rural population with lower income is more inclined to have poorer health because they lived in remote areas with limited access roads to hospitals and health care facilities. The data was collected by using survey questionnaire. The survey questionnaire was created by researchers and it consists of four main sections, which is Section A, B, C and D. Section A is related to the demography background, Section B is related to the source of information and knowledge on health, Section $\mathrm{C}$ is to testing the health literacy of the respondents on disease and its causes; as well as their selfhealth care, and Section D is related to using health services. A pilot study was carried out to test the questionnaires before it applied to study field. There are several health literacy assessment tools that have been developed in order to evaluate health literacy level, namely Test of Functional Health Literacy in Adults (TOFHLA), Rapid Estimate of Adult Literacy in 
Medicine (REALM) and Newest Vital Sign (NVS). Applying conventional health literacy measurements such as TOHFLA, REALM, and NVS among rural communities has its own limitations. This is because of the standard of these HL measurements is a high level. Not only all the questions are in English, but also the terms used in the questionnaire are quite scientific and technical, which requires reading comprehension and numeracy skills that allow an individual to function in health care management. Consequently, these measurements are not suitable to measure health literacy especially among populations in rural areas considering the fact that most of them come from lower education background and some of them can't even read and write (illiteracy problems). Alternatively, Likert Scale was used as a measurement of the data for this study. Most of the multiple choices question from the questionnaire was based on ordinal scale in which a number was used to represent an answer. For instance, a range of numbers from 5 to 1 is considered as values to represent an answer, which is, $\mathbf{5}$ - Very knowing, 4 Knowing, $\mathbf{3}$ - Not sure, $\mathbf{2}$ - Least knowing and $\mathbf{1}$ - Not knowing at all. In this study, face-to-face interview was conducted during doing a survey questionnaire. Meaning to say, the researcher asked the community and help to fill in the form using simple languages. Stratified sampling technique was applied in choosing the numbers of samples and locations. In this study, there are 10 to 12 samples were selected from each of locations. The locations for conducting the data collection was focus on rural areas. About 92 respondents were interviewed using the same survey forms in the eight selected locations, namely $\mathrm{Kg}$ Paginatan, $\mathrm{Kg}$ Matupang, $\mathrm{Kg}$ Sagindai, $\mathrm{Kg}$ Tampios, Kg Maringkan, Kg Pinausuk, Kg Tarawas and Kg Paus. The location of each of the respondents' house, the nearest health facilities and hospital district were manually captured using Global Positioning System (GPS). These data were then transferred into ArcGIS 10.0 software to conducting the spatial analysis. 


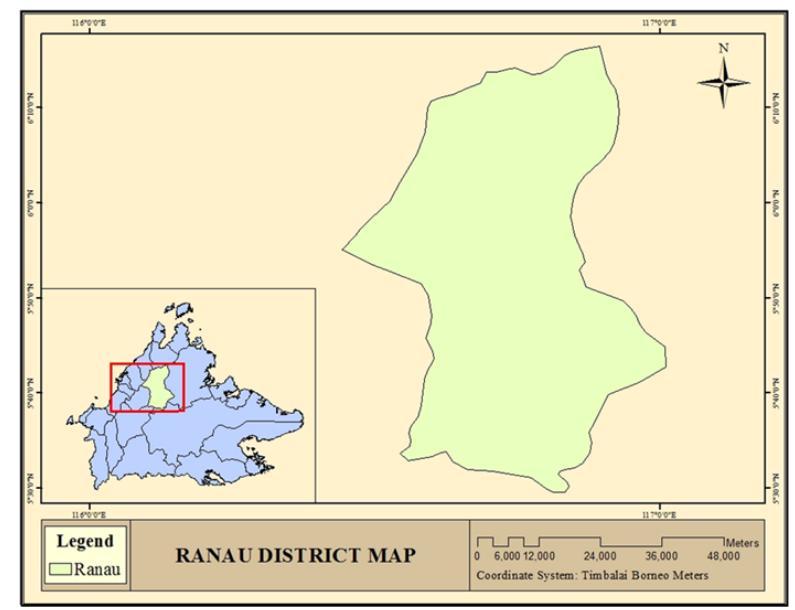

Figure 1: Study Area Map

There are two analysis was used to analyzed the data, which are Inverse Distance Weighted (IDW) interpolation and Overlay analysis. This two analysis were used to determine the distribution pattern of data. The difference between these two analysis is IDW interpolation analysis is able to analyze only one variable, while overlay analysis can analyze more than one variables. Inverse Distance Weighted (IDW) interpolation method was applied to shows the spatial distribution of data points. IDW interpolation makes the assumption that things that are close to one another are more alike than those that are farther apart. This method will be used by a state in which there are enough sample points (at least 14 points) with a suitable dispersion in local scale levels. The main factor affecting the accuracy of inverse distance interpolator is the value of the power parameter $\mathrm{p}$ (Burrough and McDonnell, 1998). Figure 2 (a), (b), (c), (d) below shows the map display for IDW interpolation analysis for each of the variables. 


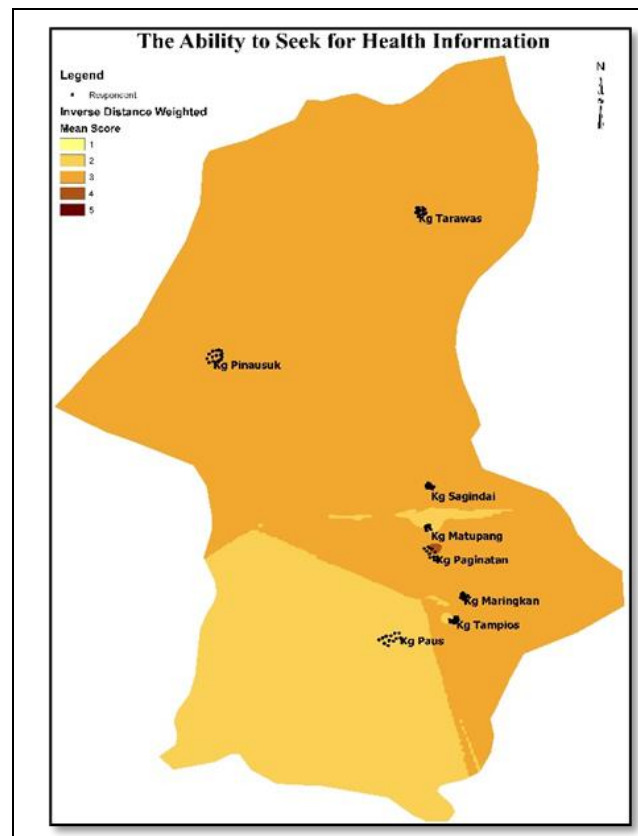

Figure 2 (a)

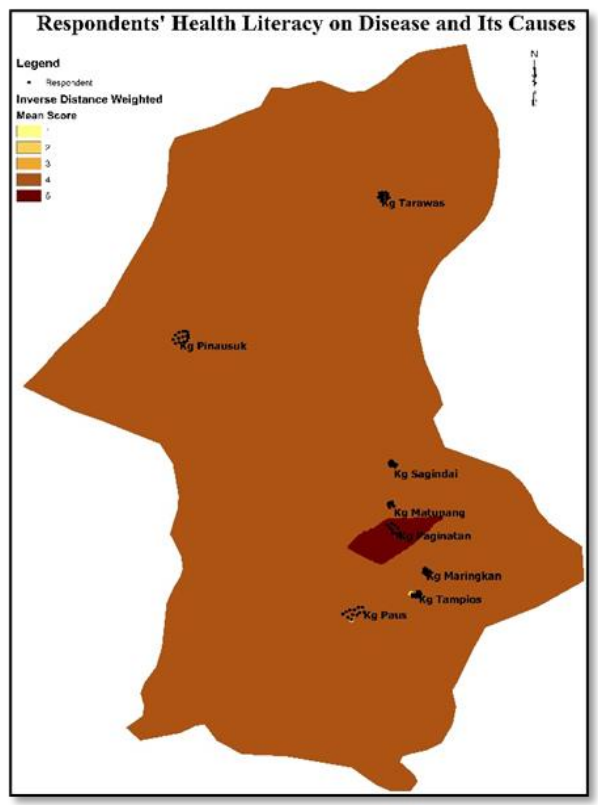

Figure 2 (c)

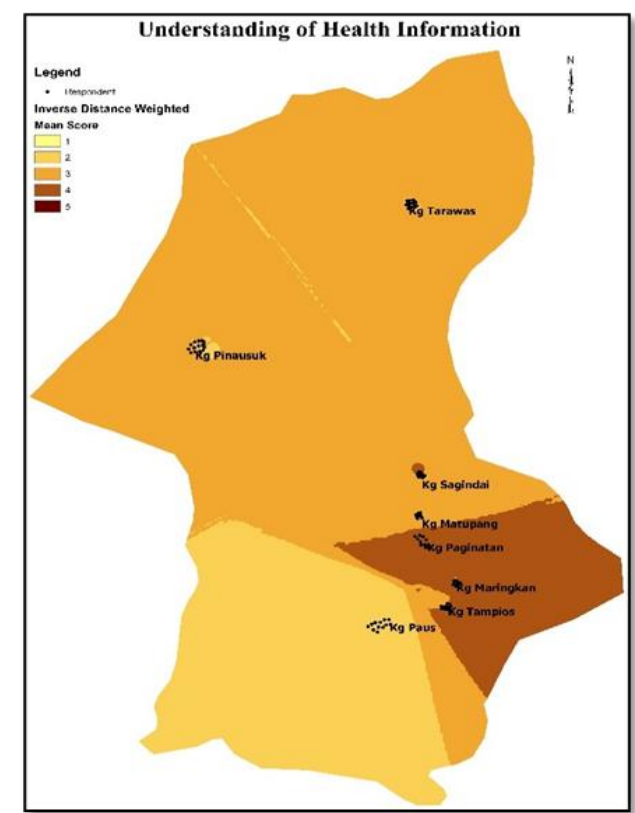

Figure 2 (b)

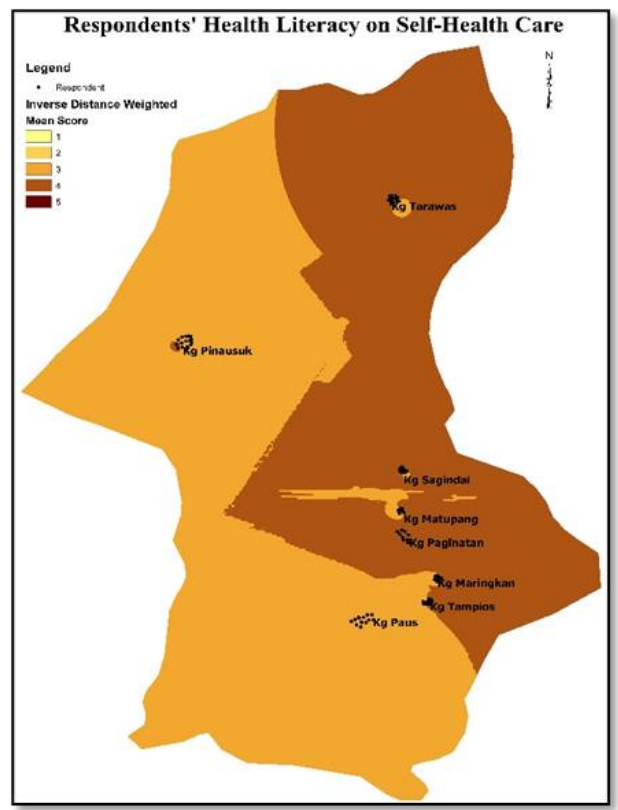

Figure 2 (d)

Figure 2 (a), (b), (c) and (d): IDW interpolation

Mean scores for each of the items of the variables was calculated first before running the IDW interpolation analysis. The result of analysis IDW 
interpolation is display by using color-coding to determine the values of variables in a map format. The darker the color is, the higher its value and the brighter the color is, the lower its value. The distribution color pattern shows in the maps are based on the mean scores of each of the items in variables. Figure 2 (a) shows the ability to seek health information among rural population in Ranau. The average mean score for this variable is 2.20 , which means that their capability to obtain health information is highly limited. In Figure 2 (b), the average mean score for their understanding of health information is 2.59 , which means that they have low understanding of health information that they received. Based on Figure 2 (d), the average mean score for their HL on disease and its causes are quite adequate, which is 3.55. The average mean score for their HL on self-health care is also quite adequate, which is 3.02 (Figure 2 (d)).

Firstly, the data values were calculated to get mean scores for each of items of the selected variables before runs the interpolation analysis. After the mean scores for each of the items of the variables calculated, IDW interpolation analysis was conducted to show the distribution pattern of each of the variables. Next, overlay method was applied using intersect operation to run the analysis. Then, the data were reclassified into high and low value using grid codes $(1,2)$, which is code 1 is classified as a high value from 5 to 4 value and code 2 is classified as a low value from 2 to 1 value. To run the overlay analysis using intersect operation, conversion of the data from raster to polygon was needed. This is because of the interpolation data are still considered as floating points (unsolid data). Therefore, the raster data where the same values of each group (high) and (low) need to be converted to polygon to generate a solid data. Lastly, overlay analysis was conducted using intersect operation to run the analysis between two selected variables (Refer to Diagram 1).

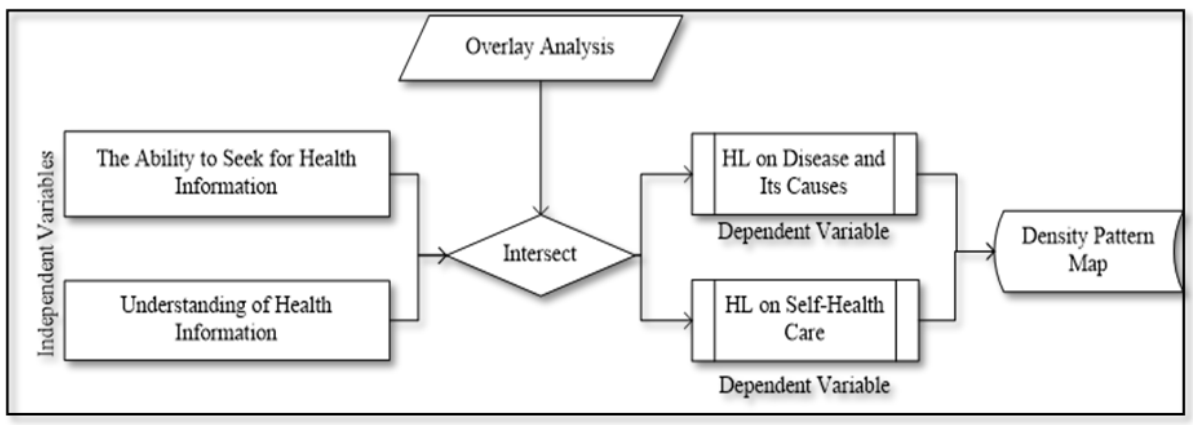

Diagram 1: Overlay analysis using intersect operation 
Diagram 1 shows that the selected variables of independent and dependent variables which were involved in overlay analysis using intersect operation. The ability to seek for health information is independent variable, which is related to the respondents capability to find, obtain and receive health information from various sources which included mass media such as television, radio, newspaper, internet, friends or family, doctors or healthcare providers' advices, seminars and talks and traditional health knowledge. Understanding of health information is independent variable, which is related to their understanding on health information in recognizing diseases, causes, symptoms, medicines, types of treatment and prevention. HL on disease and its causes; and HL on self-health care are consider as dependent variables, which is related to testing their basic health knowledge as they practice in their health routine life. Therefore, overlay analysis was conducted to see whether they do really find, understand and use health information which they obtained and received from sources of health information and then applied it to their daily health knowledge or not. Therefore, each of the layers of independent variables was intersected with each of the layers of dependent variables using method (high-high), (low-low), (high-low) and (low-high). The reason to intersect between (high-high) and (low-low) variables is to shows that if there are parallel relation between those two variables, while the intersection between (high-low) and (low-high) is to show that if there are differences between those two variables. The output of overlay analysis will be display as density pattern map in which the result of intersecting shows a polygon or few polygons overlap with the points that contain attribute information.

\section{Results and discussion}

The study mapped the pattern distribution of health literacy level among communities in rural areas. The result shows the high and low level of health literacy using overlay analysis to intersect the layers between two selected variables. For this analysis, color coding, users a single color to symbolize the high and low value of health literacy level. 


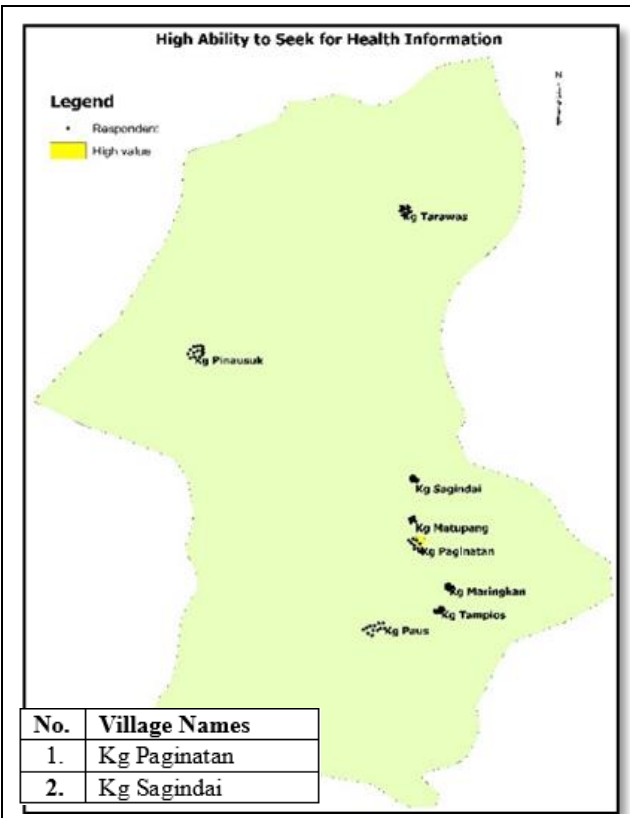

Figure 3 (a): High Ability to Seek for Health Information

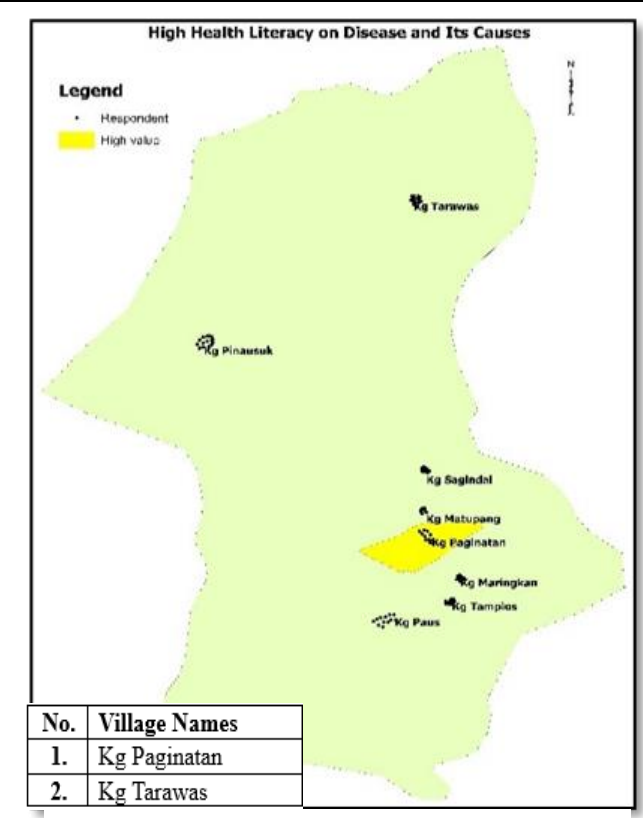

Figure 3 (b): High Health Literacy on Disease and Its Causes

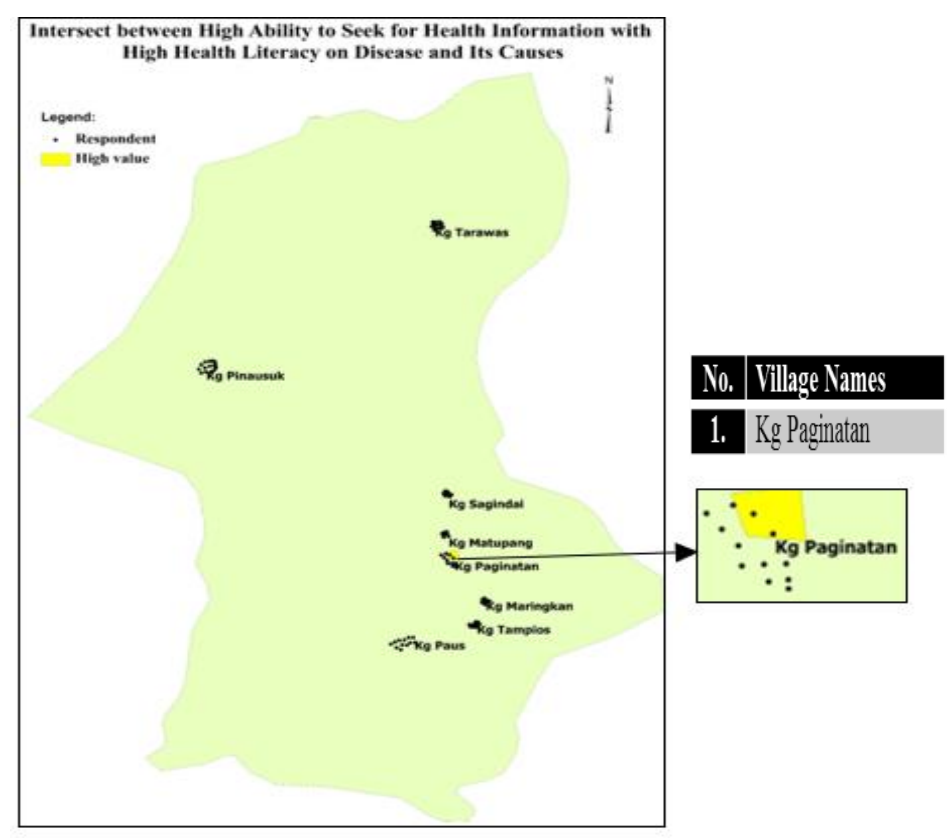

Figure 3 (c): Intersect between High Ability to Seek for Health Information with High Health Literacy in Disease and Its Causes

Based on Figure 3 (a), the capability of respondents in $\mathrm{Kg}$ Paginatan and $\mathrm{Kg}$ Sagindai to obtain health information is high compared to other villages. 
Meanwhile, in Figure 3 (b) shows that respondents' health literacy on disease and its causes are also high in $\mathrm{Kg}$ Paginatan and $\mathrm{Kg}$ Tarawas. Thus, when these two layers (Figure 3 (a) and Figure 3 (b)) intersect, the result shows that only respondents in $\mathrm{Kg}$ Paginatan have high ability to obtain health information along with their HL on disease and causes. Although it can be seen that there's a relation between high ability to seek health information and high health literacy on disease and its causes, in which it suggests that the higher their potential to find and obtain health information, the better their health literacy is, the fact that Kg Sagindai has high capability to seek for health information but low in health literacy on disease and causes of disease shows that having capacity to find and obtain health-related information doesn't mean that their health literacy are likely limited. 


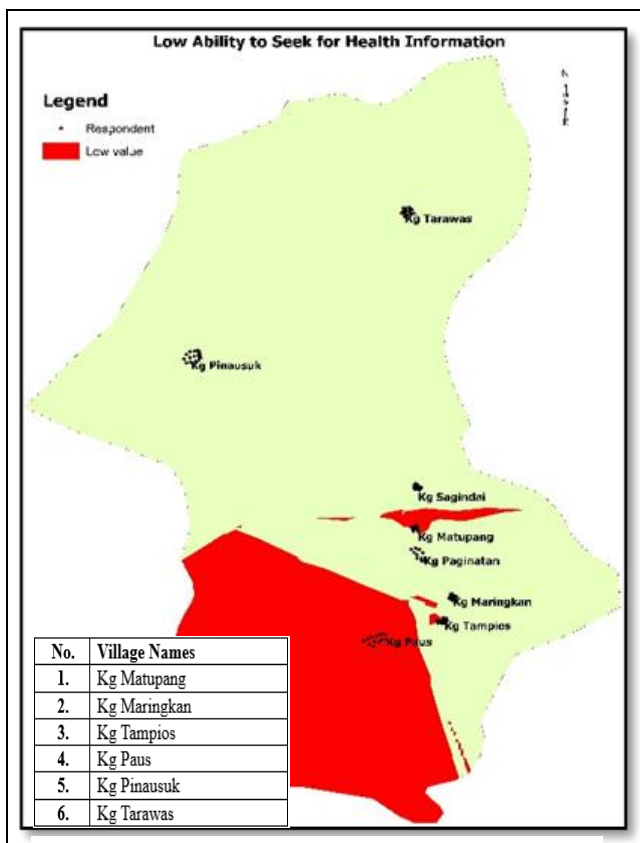

Figure 5 (a): Low Ability to Seek for Health Information

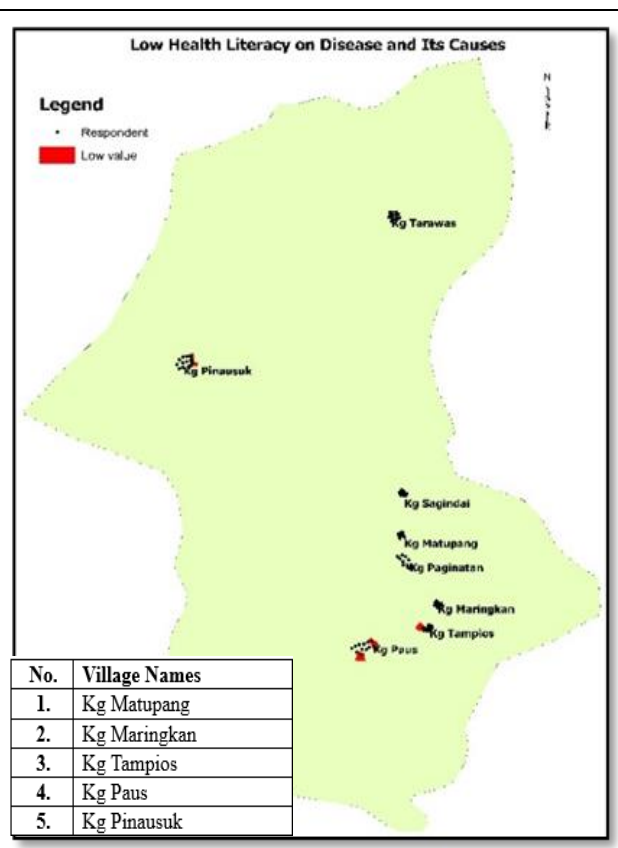

Figure 5 (b): Low Health Literacy on Disease and Its Causes

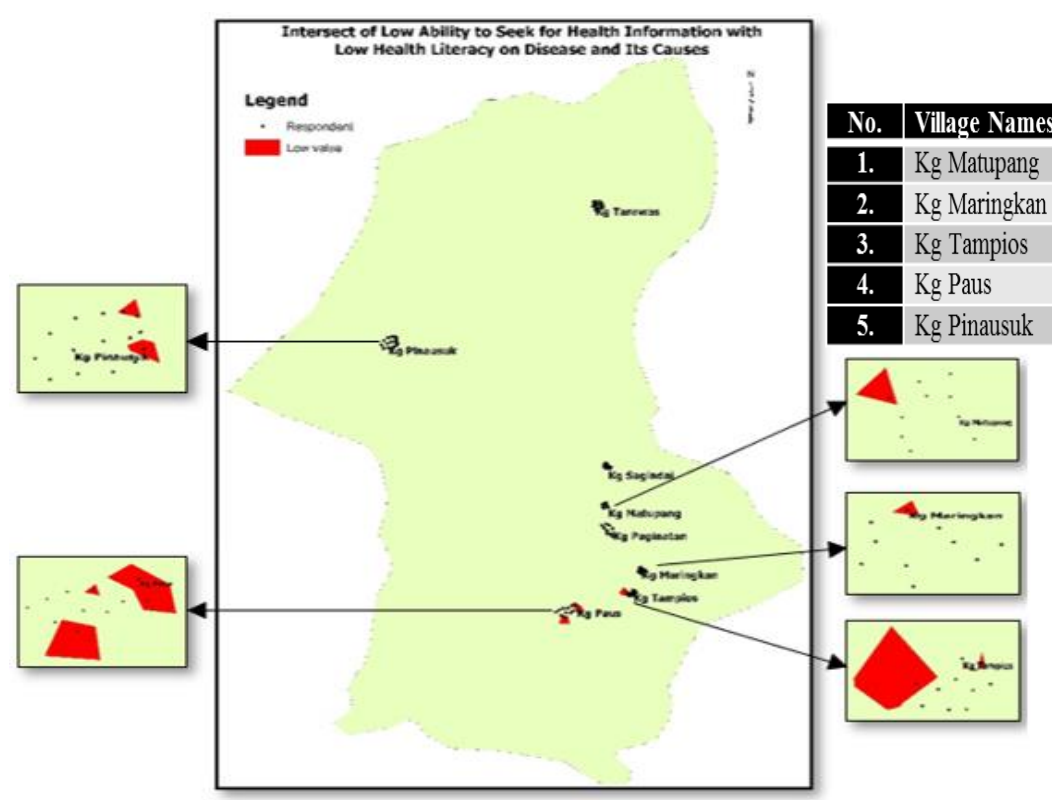

Figure 5 (c): Intersect between Low Ability to Seek for Health Information with Health Literacy on Disease and Its Causes

Figure 5 (a) shows that most of the respondents in $\mathrm{Kg}$ Matupang, $\mathrm{Kg}$ Maringkan, Kg Tampios, Kg Paus, Kg Tarawas and Kg Pinausuk have low 
access to seek for health information. In Figure (b), respondents in $\mathrm{Kg}$ Matupang, Kg Maringkan, Kg Tampios, Kg Paus and Kg Pinausuk have low health literacy on disease and its causes. When these two layers intersect (Figure 5 (c)), the output shows that Kg Pinausuk, Kg Paus, Kg Matupang, $\mathrm{Kg}$ Maringkan and $\mathrm{Kg}$ Tampios have low capability to obtained health information which caused their health literacy on disease and causes were likely limited. This suggests that the more limited their access to source information on health, the poorer their HL on disease and its causes. 


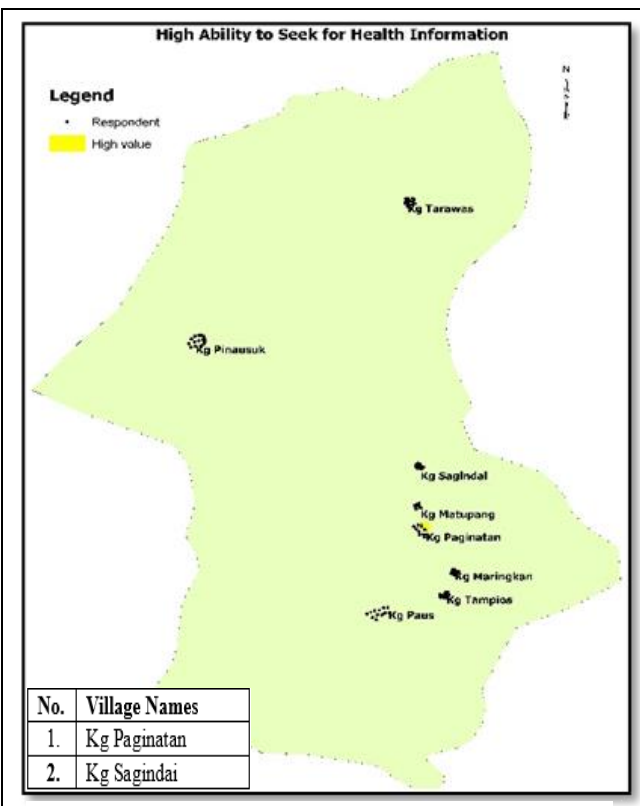

Figure 6 (a): High Ability to Seek for Health Information

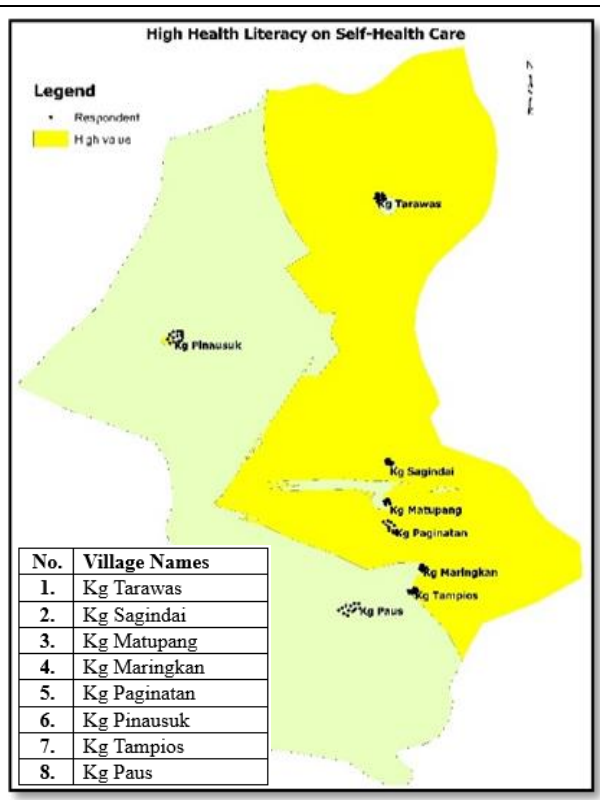

Figure 6 (b): High Health Literacy on Self-Health Care

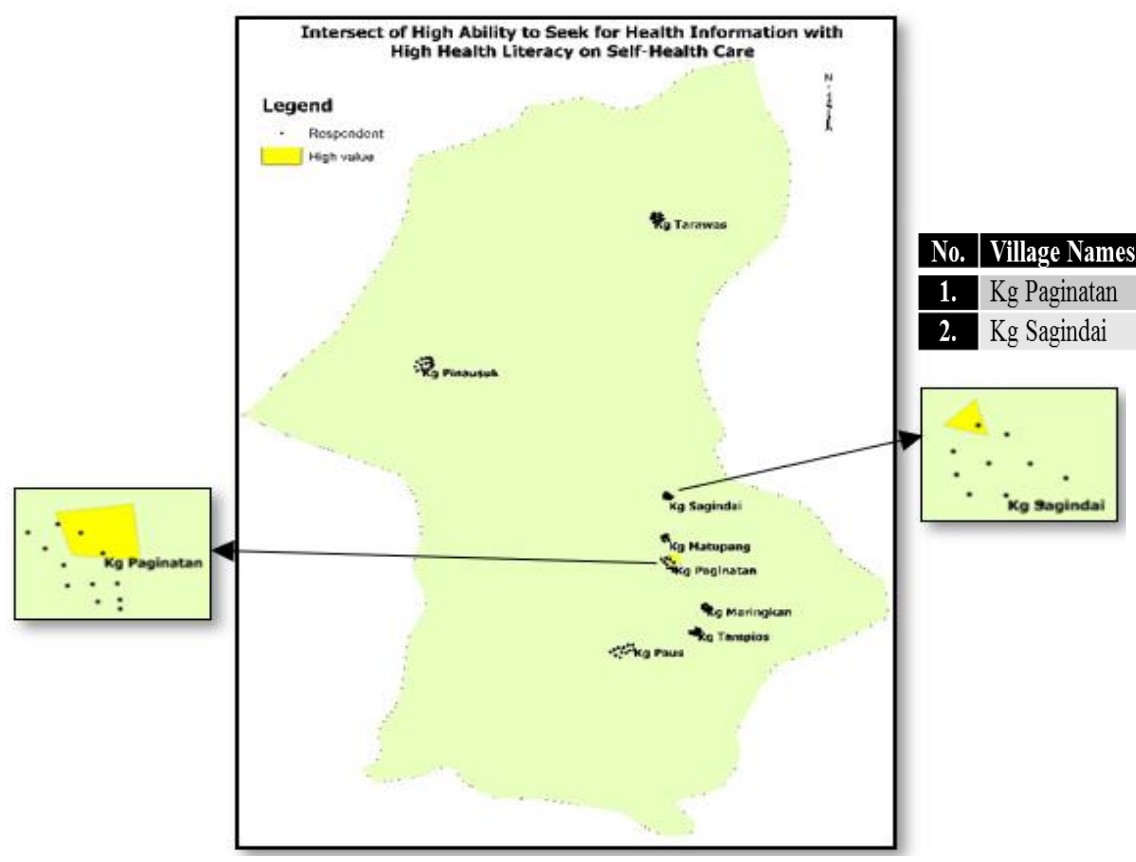

Figure 6 (c): Intersect between High Ability to Seek for Health Information with Health Literacy on Self-Health Care 
Based on Figure 6 (a), it can be seen that only $\mathrm{Kg}$ Paginatan and $\mathrm{Kg}$ Sagindai have high capability to obtained health information. Figure 6 (b) clearly shows that all the villages have high health literacy on self-health care. When these two layers (Figure 6 (a) and Figure 6 (b)) intersect, it shows that only Kg Paginatan and Kg Sagindai have high ability in searching for health information along with their health literacy on self-health care. This suggests that there's a parallel relation between high ability to seek for health information with high HL on self-health care, in which the higher their potential to access and obtain source of health information, the better their basic HL on self-health care is. 


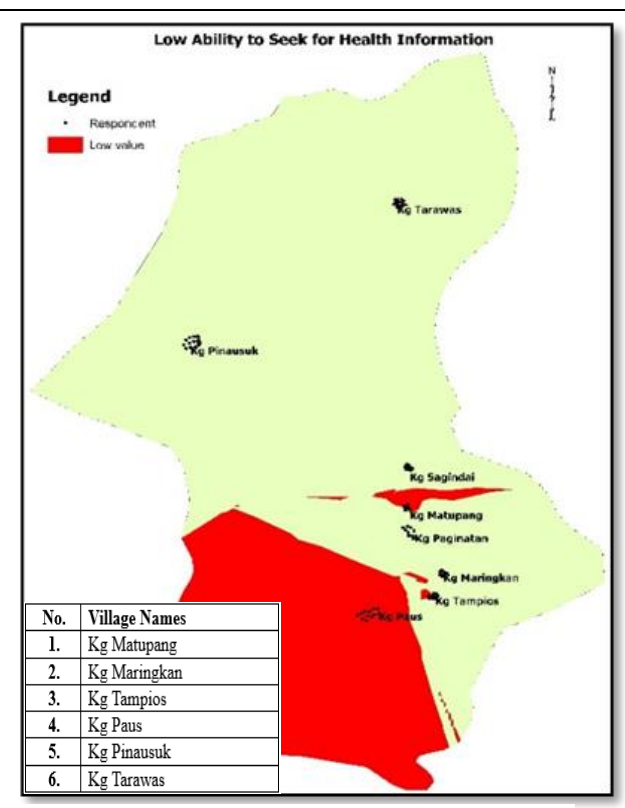

Figure 7 (a): Low Ability to Seek for Health Information

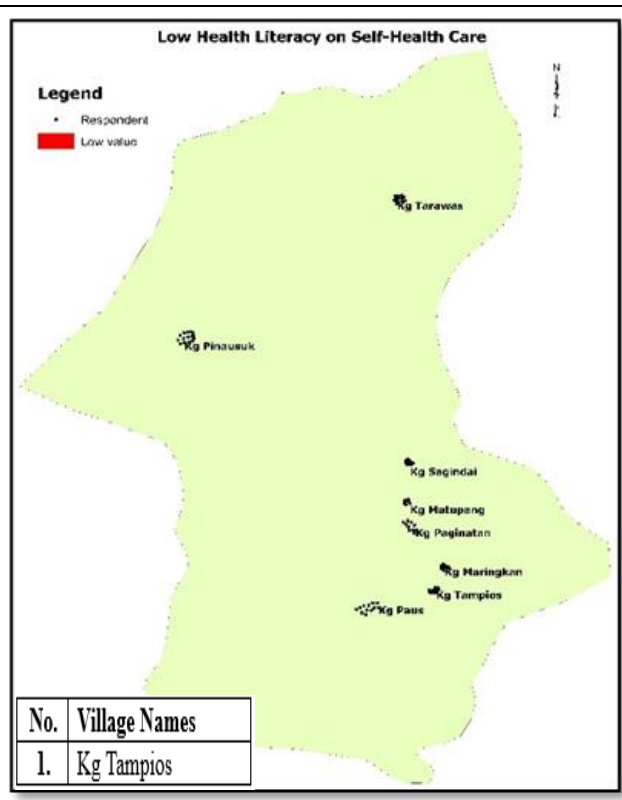

Figure 7 (b): Low Health Literacy on Self-Health Care

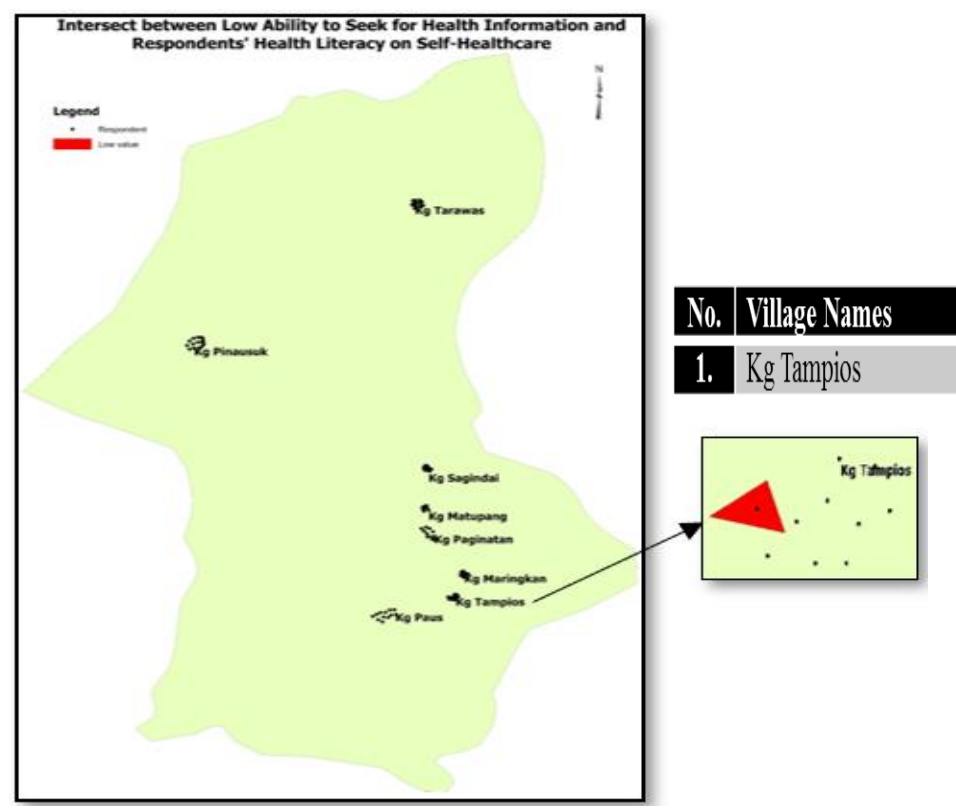

Figure 7 (C): Intersect between Low Ability to Seek for Health Information with Low Health Literacy on Self-Health 
According to Figure 7 (a), all the villages except $\mathrm{Kg}$ Paginatan and $\mathrm{Kg}$ Sagindai have a low ability to seek health information. Only Kg Tampios has poor HL on self-health care compared to the other villages (Figure 7 (b). Therefore, when these two layers (Figure 7 (a) and Figure 7 (b)) intersect, it shows that only Kg Tampios has low capability to find health information and limited health literacy on self-health care. This suggests that even though respondents in all villages except $\mathrm{Kg}$ Tampios have low capability to seek and obtain health information, it does not mean that they have poor health literacy skills on self-health care. 


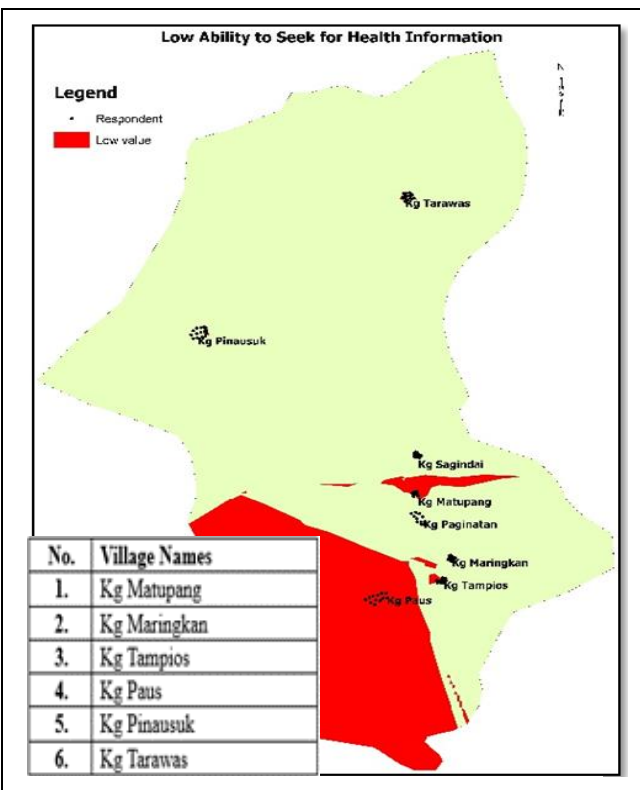

Figure 8 (a): Low Ability to Seek for Health Information

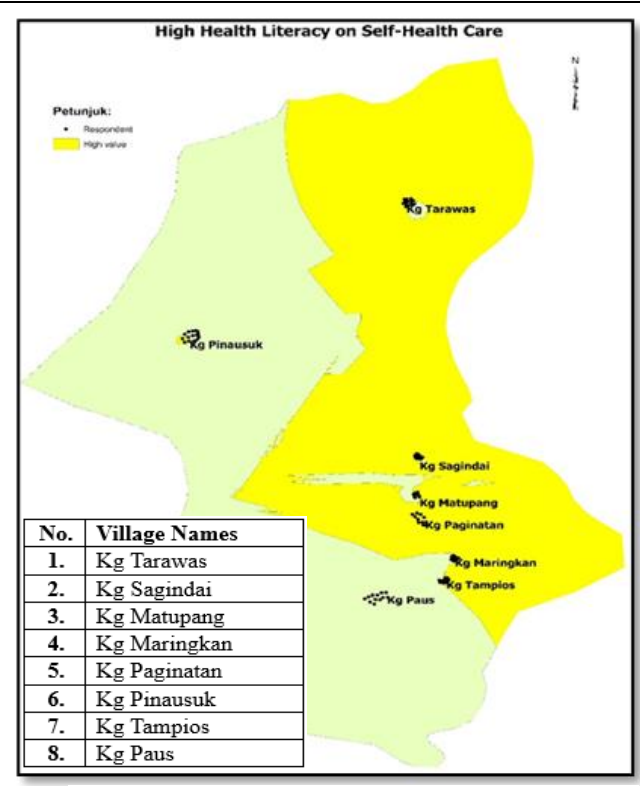

Figure 8 (b): High Health Literacy on Self-Health Care

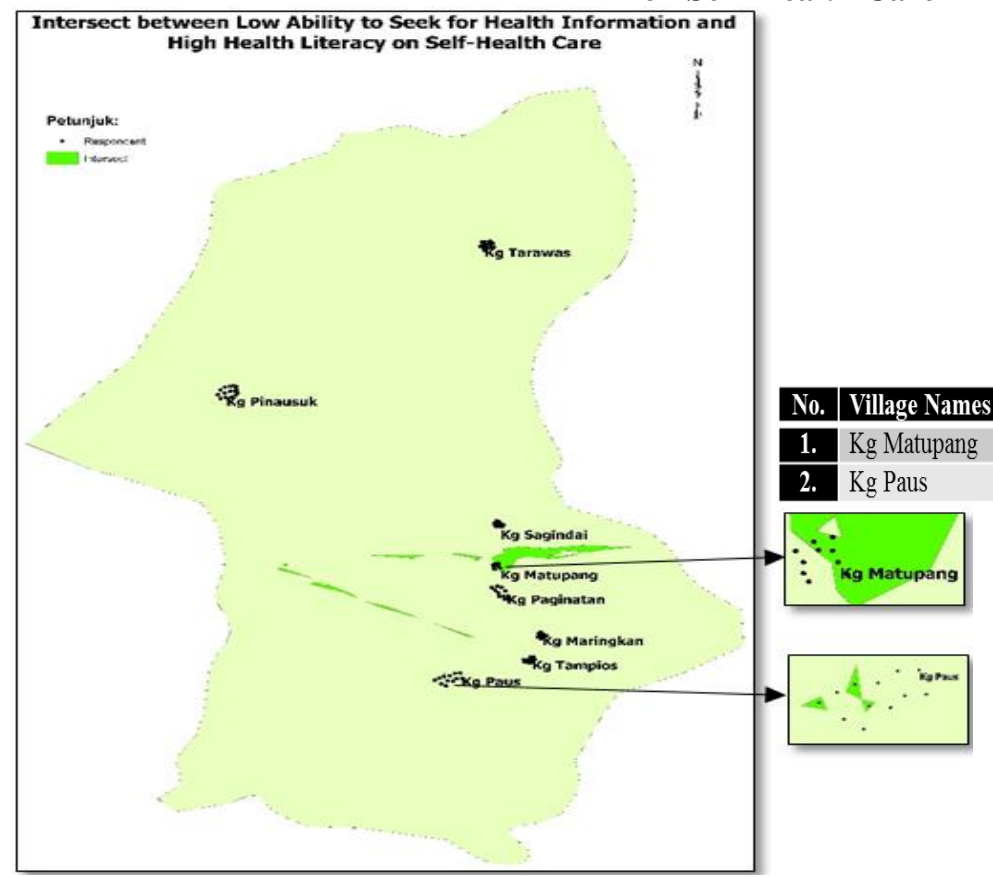

Figure 8 (c): Intersect between Low Ability to Seek for Health Information with Health Literacy on Self-Health Care 
Based on Figure 8 (a), respondents in all villages excluding Kg Paginatan and $\mathrm{Kg}$ Sagindai have low ability to seek for health information. On the contrary, they have high health literacy on self-health care. When these two layers of low-high variables (Figure 8 (a) and Figure 8 (b)) overlap, the result shows that only $\mathrm{Kg}$ Matupang and $\mathrm{Kg}$ Paus were intersected. As a result, it shows that there's unparalleled relation between low ability to seek for health information with high health literacy on self-health care. This indicates that even though they have poor access to obtain health information, they basically have better understanding on how take a good care of themselves in their daily life. 


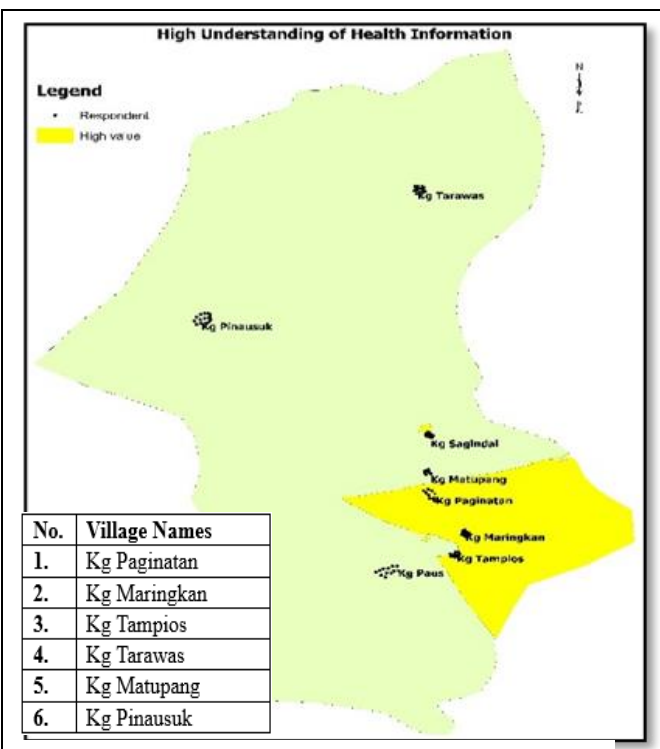

Figure 9 (a): High Understanding of Health Information

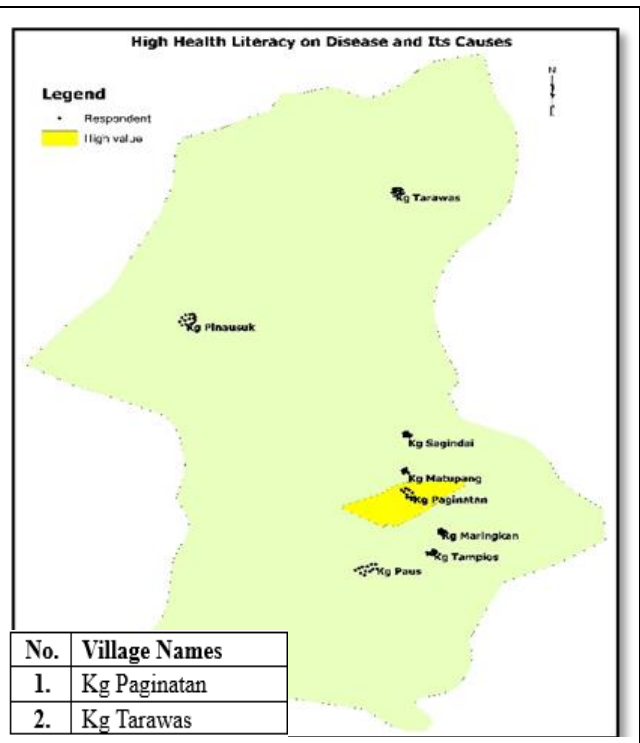

Figure 9 (b): High Health Literacy on Disease and Its Causes

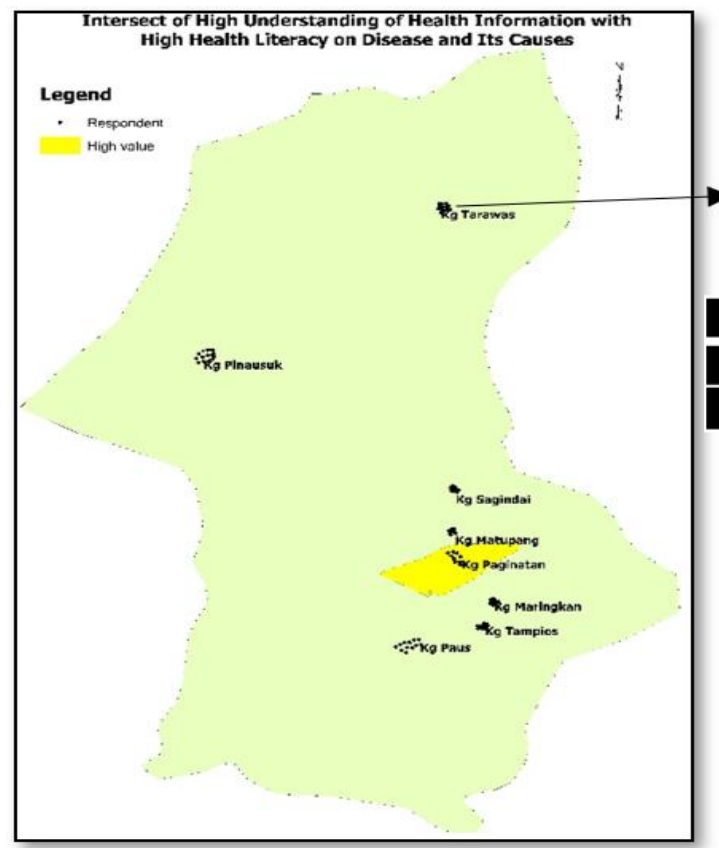

Figure 9 (c): High Understanding of Health Information with High Health Literacy on Disease and Its Causes

Figure 9 (a) shows that all the villages except $\mathrm{Kg}$ Sagindai and $\mathrm{Kg}$ Paus have high understanding of health information. In Figure 9 (b) show that $\mathrm{Kg}$ Paginatan and $\mathrm{Kg}$ Tarawas have good $\mathrm{HL}$ on disease and its causes. 
Therefore, when these two layers (Figure 9 (a) and Figure 9 (b)) intersect, the output shows that only respondents in Kg Paginatan and $\mathrm{Kg}$ Tarawas applied their understanding of health information which they obtained from various sources information on their daily health knowledge on disease and its causes. 


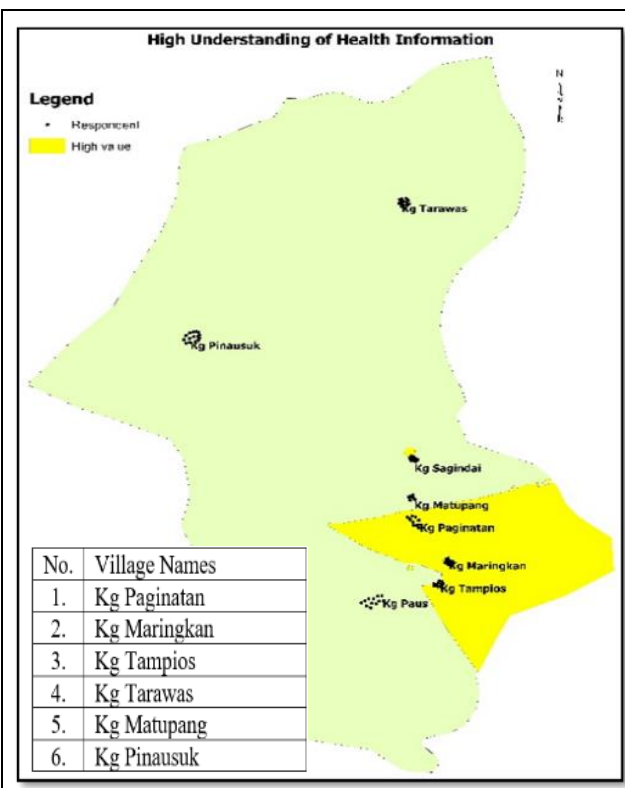

Figure 10 (a): High Understanding of Health Information

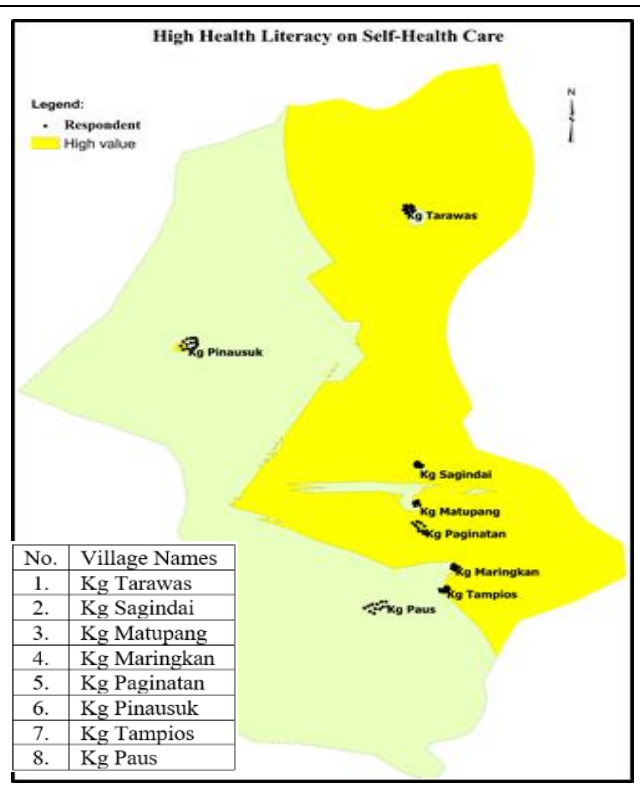

Figure 10 (b): High Health Literacy on Self-Health Care

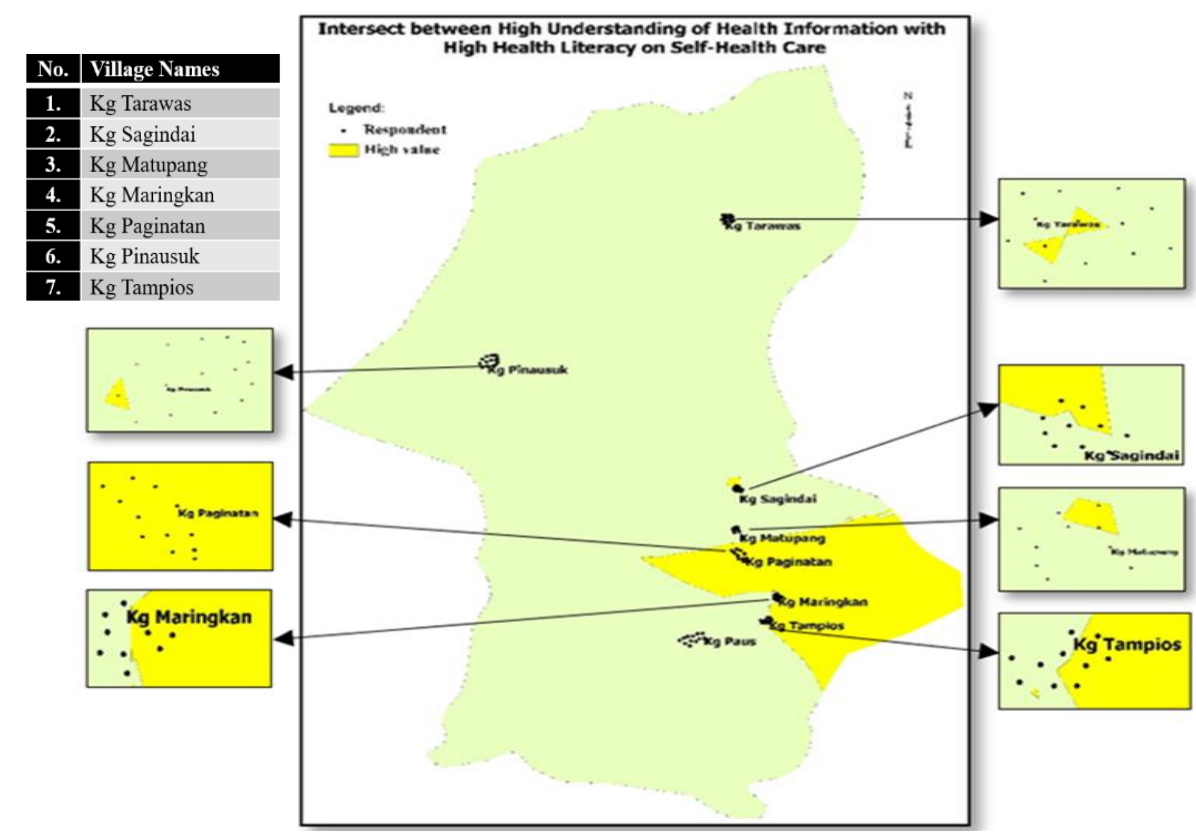

Figure 10 (c): Intersect between High Understanding of Health Information with High Health Literacy on Self-Health Care

Based on Figure 10 (a), Kg Paginatan, Kg Maringkan, Kg Tampios, Kg Tarawas, Kg Matupang, and Kg Pinausuk have high understanding of health 
information. While in Figure 10 (b), respondents in all the villages have good health literacy on self-health care. When these two layers (Figure 10 (a) and Figure 10 (b)) intersect, respondents in all the villages except $\mathrm{Kg}$ Paus have capacity to process and retain health information in which they applied it on their health literacy skills in daily life. 


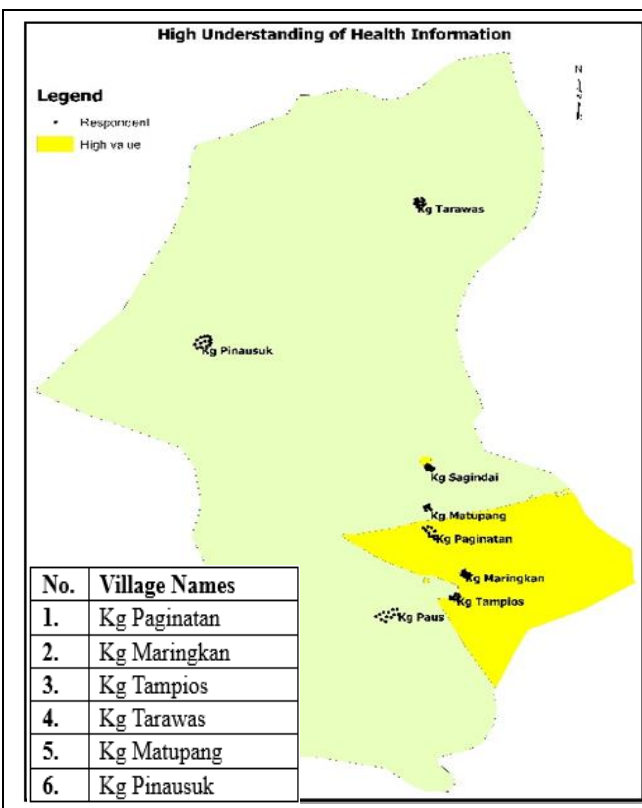

Figure 11 (a): High Understanding of Health Information

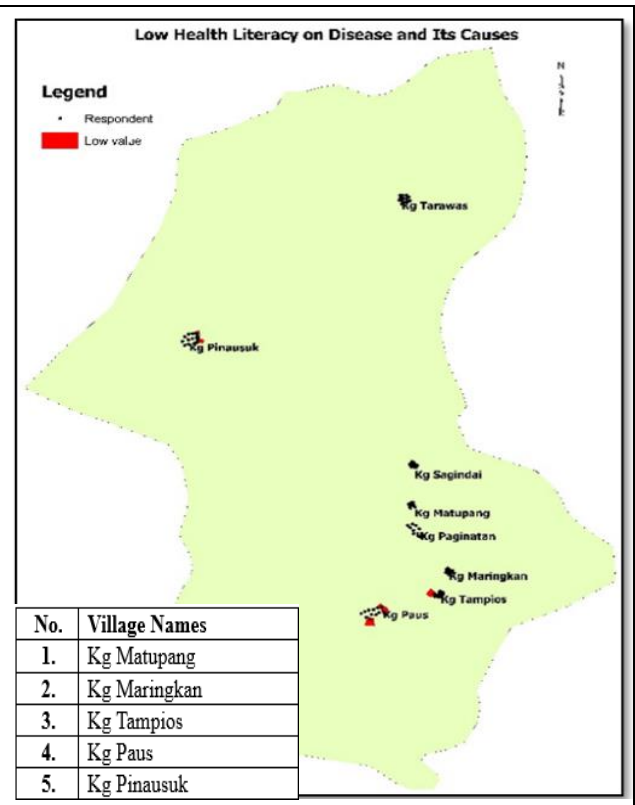

Figure 11 (b): Low Health Literacy on Disease and Its Causes

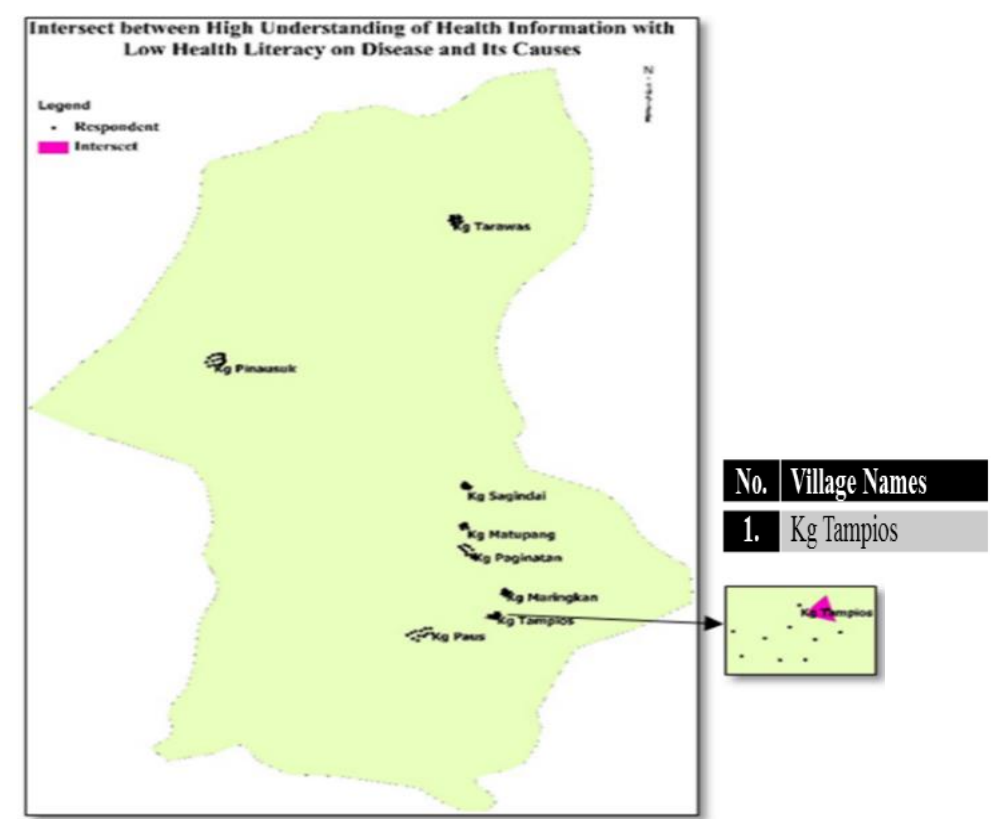

Figure 11 (c): Intersect between High Understanding of Health Information with Low HL on Disease and Its Causes

Figure 11 (a) shows that all the villages except $\mathrm{Kg}$ Paus and $\mathrm{Kg}$ Sagindai have good understanding of health information. In Figure 11 (b), $\mathrm{Kg}$ 
Matupang, Kg Maringkan, Kg Tampios, Kg Paus and Kg Pinausuk have low $\mathrm{HL}$ on disease and its causes. Outputs of these high-low layers intersect shows that there's a difference between those two variables. This means that even though respondents in $\mathrm{Kg}$ Tampios understand information related to health in which they find, received and obtained from various sources information, but they didn't apply it on their health literacy skills in daily life. 


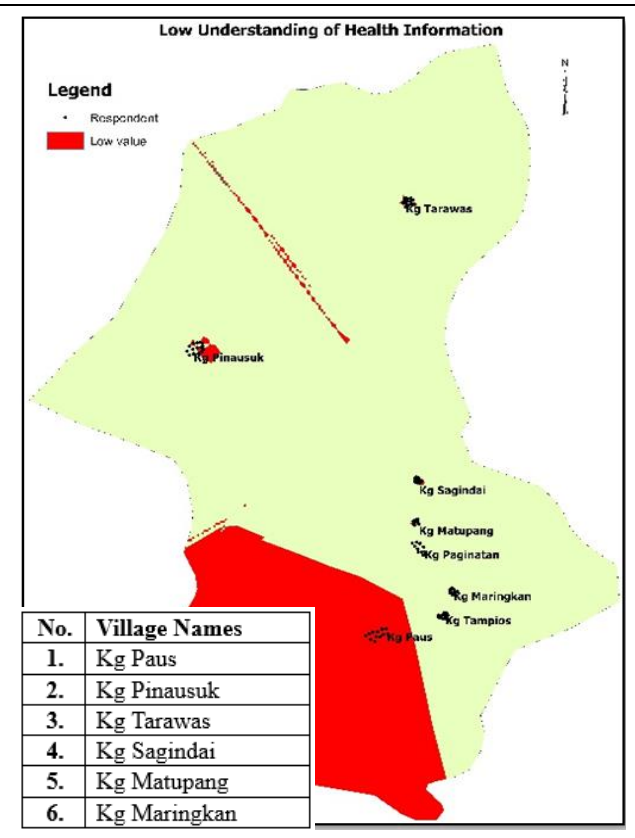

Figure 12 (a): Low Understanding of Health Information

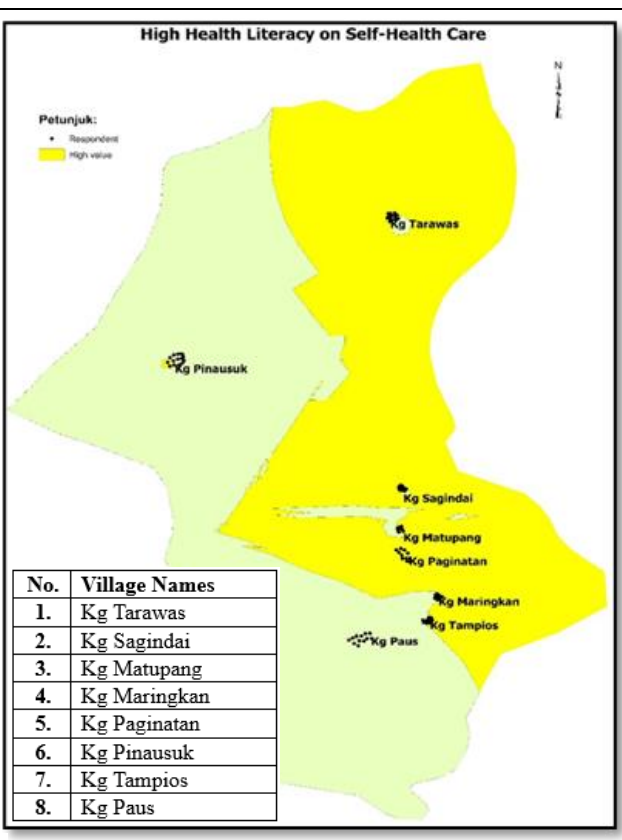

Figure 12 (b): High Health Literacy on Self-Health Care

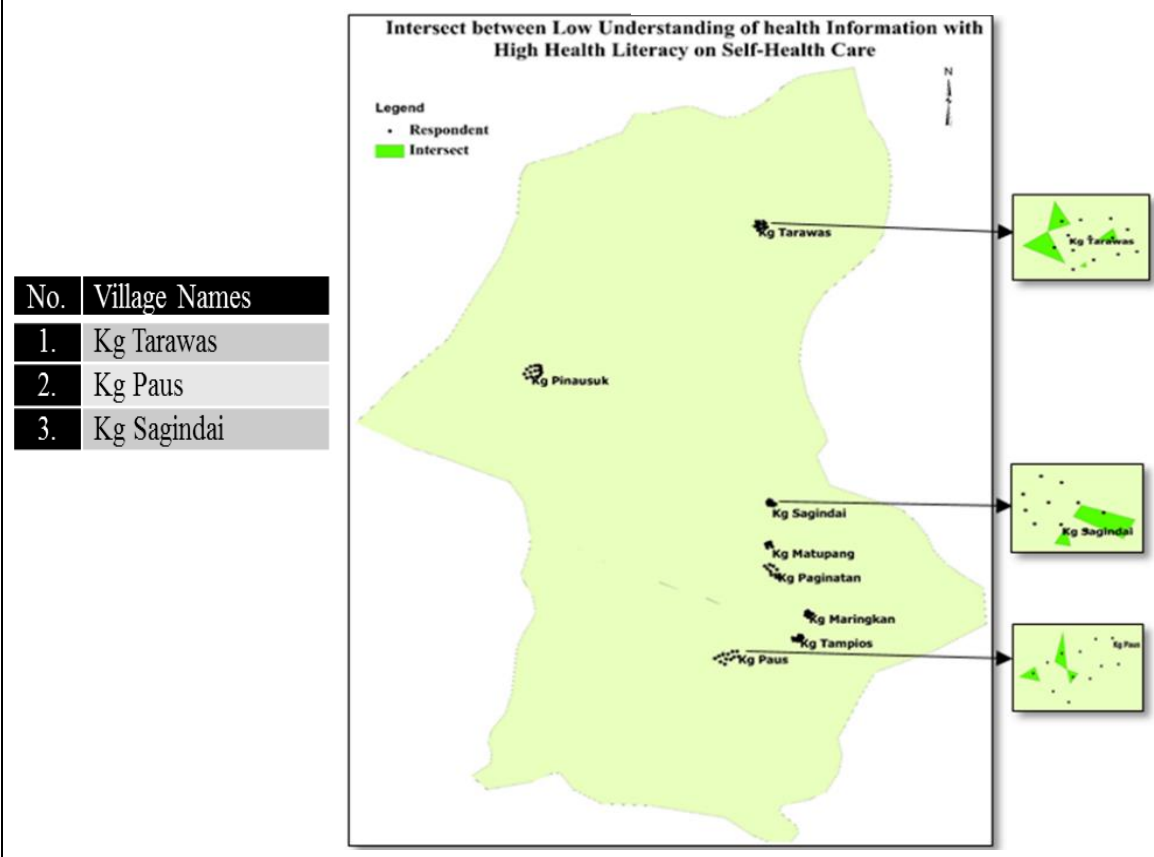

Figure 12 (c): Intersect between Low Understanding of Health Information with High Health Literacy on Self-Care 
In Figure 12 (a), respondents in $\mathrm{Kg}$ Paus and some of the respondents in $\mathrm{Kg}$ Pinausuk, Kg Tarawas, Kg Sagindai, Kg Matupang, and Kg Maringkan have low understanding of health information. Meanwhile, all respondents in the villages have high health literacy on their self-health care. The result of the overlap of low-high variables between Figure 12 (a) layer with Figure 12 (b) layer shows that only three villages, namely Kg Tarawas, Kg Paus and $\mathrm{Kg}$ Sagindai were intersected. Such situation indicates that even though respondents in these three villages have poor understanding of health information related to diseases, causes of disease, symptoms, medicines, and types of treatment that they have received, but their health literacy on basic self-health care knowledge is literally good.

\section{Discussion}

To summarize, there is no relation between respondents' ability to seek health information with HL on disease and causes of disease; as well as HL on self-health care. Rural communities in Kg Matupang, Kg Maringkan, $\mathrm{Kg}$ Tampios, Kg Pinausuk, Kg Tarawas and Kg Paus have low ability to seek health information due to the lack of access to mass media such as television, radio, newspaper and internet that can hinder them from obtaining, receiving, understand and apply health information on their daily life. They have limited access to health information and some of the villages, for example, $\mathrm{Kg}$ Paus did not have network coverage for them to access to the internet. There is no rural clinic provided as health services to the community in $\mathrm{Kg}$ Paus. They need to go to the nearest clinic such as Rural Clinic Tampios to get healthcare treatment and medicines supply. However, some of the respondents prefer to self-treatment using traditional medicines or buy medicines at grocery store instead of going to the clinic because of certain reasons, such as they have no transportation, the transport fare is quite pricey due to the long distance and bad roads condition. Out of 92 respondents, about $44.6 \%$ respondents did not have access to the internet.

Despite the fact that $\mathrm{Kg}$ Paus and $\mathrm{Kg}$ Matupang have low ability to obtain health information, they have good health literacy on self-health care. This is because most of the respondents have traditional knowledge of selfhealth care and treatment, in which they still practice and applied them to their health knowledge skills in everyday life. Meanwhile, respondents in $\mathrm{Kg}$ Paginatan have unlimited access to health information because they have specialist doctor in Paginatan Health Clinic, in which they can seek health advice face to face with the doctors. The distance from the village to the health services is quite close, which took them five to ten minutes of walking and it has made them easier to commute back and forth. People who live in nearby villages, such as Kg Sagindai, Kg Maringkan, $\mathrm{Kg}$ Matupang, and Kg 
Tampios also often sought health care treatment at the same health services. This is because there are no doctors or health experts in Rural Clinic Tampios and Rural Clinic Matupang for them to get a better health care treatment. Apart from that, seminars and health talks were frequently held by health care providers to the villager audience in Kg Paginatan compared to the other villages. This is the reason why respondents in Kg Paginatan have both high HL level on disease and its causes, and HL on self-health care, respectively. Nevertheless, respondents in Kg Sagindai also have high ability to seek health information, but their HL on disease and its causes was likely low. The reason for this is that some of them unable to distinguish if the information gained is accurate or not and they have poor knowledge of authoritative health information sources in recognize which authoritative sites to refer to.

Although the majority of the respondents in all villages except $\mathrm{Kg}$ Paginatan have poor health literacy on health knowledge such as disease and the causes of disease, but respondents in all the villages have high HL on self-health care. This means that they know the most basic health knowledge on how to take care of their health in their daily life such as healthy eating habits, healthy diets, healthy lifestyle, and healthy environments and so on. Most of them received these kinds of health information from the doctor's advice, seminars, and health talks. The reason why majority of the respondents have poor HL of health information such as disease and the causes of disease is because they were more focused on seeking out information related to their health problem or family member's illness instead of widening their knowledge on other types of disease. In spite of the fact that rural community lack of access to health information and infrastructures, in which might lead to high prevalence of limited health literacy, in which may affect their health status, yet so far most of the respondents don't have severe illness such as cancer or infectious disease. Some of them suffer from chronic disease such as hypertension or high blood pressure and diabetes, while some of them have common minor health problems such as joint pain, bone, knee and hip pain, migraine, gastric and so on. This has something to do with their lifestyle and eating habits. to rural people who lived in remote areas which is quite far away from town for example Kg Paus, it's really hard for them to buy foods from outside. They said only once a week there will be a van that sell fresh meat and vegetables comes to the village. Some other day, they had to go fishing in the river and planting vegetables on their own for their daily foods. 
In terms of their understanding of health information, they are most likely have least understanding on health information, which they find, obtained and received such as symptoms, causes of disease, types of treatment, types of disease, medicines and prevention. Most of respondents in Kg Paus and $\mathrm{Kg}$ Pinausuk have poor understanding on health information due to the limited access to health information sources. Even though respondents in $\mathrm{Kg}$ Tampios have high understanding on health information, but they have low health literacy skills on disease and its causes. This is because they can read, see, hear and understand health information that they've received only in a day, on the next day they forgot the health information. Hence, one should have high capacity to process and use and apply health-related information to improve their health literacy skills. There is unparalleled relation between low understanding of health information with high $\mathrm{HL}$ on self-health care, in which $\mathrm{Kg}$ Tarawas, $\mathrm{Kg}$ Paus and $\mathrm{Kg}$ Sagindai have limited understanding on health information, but they literally have good HL on self-health care. Even though they have poor understanding of health information because of the health terms used in some of health information sources, but they have good understanding of self- health care because some of them basically have traditional knowledge on how to cure and treat illness by using natural plants as a medicine.

\section{Limitations}

There were a few limitations in this study. First, the study was undertaken on a relatively small-sized population and limited to a certain geographical area in Ranau. Although, in this study was using stratified sampling in choosing the locations and population, it is suggested that similar studies can be carried out in a large scale in other rural areas and big sized population so that the findings can be generalized in which it represent health literacy level among rural communities in Ranau. Secondly, the distribution of the data is quite clustered for GIS data. It would be better if the data distributed normally so that spatial statistics analysis can be conducted. The third limitation was that the respondents are mostly consisted of females, this is due to the study was conducted during on weekends when the male members in the family were mostly away at work and some of them refused to be interviewed. It may be interesting if the study included males as respondents to evaluate their health literacy level in the same population.

\section{Conclusion}

The aim of this study is to mapping health literacy level among rural communities in Ranau district. GIS is able to identify geographic areas with low-density pattern of respondents with low health literacy (i.e., overlay analysis). Hence, it is easier for Public Health Department and Health 
Promotion Division to understand the information in a map format so they could take necessary measures with reference to the high-risk areas. Majority of the respondents prefers face-to-face communication approach such as seminars and health related-talks rather than the new media for health information. There is a need to give attention to health literacy research as it is an early intervention to prevent health problems that may occur among rural communities. Thus, apart from basic health knowledge on self-health care and health services, health knowledge in recognizing diseases, causes, symptoms, and treatments is a vital skill that everyone should have so that they can make appropriate health decisions for themselves for a better health care and well-being in their daily life.

\section{Acknowledgement}

The data collection was done under Dr. Haryati Abdul Karim's research grant which was funded by Universiti Malaysia Sabah (SBK 0369-2017). The authors wish to acknowledge the District Officer of Ranau, Village Chiefs and the members of Jawatankuasa Kemajuan dan Keselamatan Kampung (JKKK) and all the study participants for their commitments in providing the data.

\section{References}

Journal article

Abdurrahman Said Brodur, Emel Filiz \& Indrani Kalkan. (2017). Factors Affecting Health Literacy in Adults: A Community Based Study in Konya, Turkey. International Journal of Caring Sciences, Volume 10,Issue 1, Page 100.

Berkman, N.D, Davis, T.C \& McCormack, L. (2010). Health literacy: what is it? Journal of Health Communication. Vol. 15(2): 9-19.

Cossman E. Ronald, Cossman J.S, R. Jackson \& A. Cosby. (2003). Mapping high or low mortality places across time in the United States: a research on a health visualization and analysis project. Health and Place. Vol. 9, Issue 4, Pages 361-369.

Dewalt D.A., Schillinger D., Ruo B., Bibbins-Domingo K., Baker D.W., Holmes G.M., Weinberger M., Macabasco-O'Connell A., Broucksou K., Hawk V. (2012). Multisite randomized trial of a single session versus multisession literacy-sensitive self-care intervention for patients with heart failure. National Library of Medicine. Vol 125:2854-2862.

Holt James B, Heitgerd Janet L, Andrew L Dent, Kimberlee A Elmore, Brian Kaplan, Marilyn M Metzler, Koren Melfi, Jennifer M Stanley, 
Keisher Highsmith, Norma Kanarek \& Karen Frederickson Coner. (2008). Community health status indicators: Adding a geospatial component. Preventing Chronic Disease: Public Health Research, Practice and Policy.

Kondilis Barbara K., Ismene J. Kiriaze, Anastasia P. Athanasoulia \& Matthew E. Falagas. (2008). Mapping health literacy research

in the European Union: A bibliometric analysis. Plos One 3(6): e2519.

Nutbeam, D. (2008). The evolving concept of health literacy. Social Science Medicine. Vol 67: 2072-2078.

Parker. R. (2000). Health literacy: a challenge for American patients and their health care providers. Health Promotion International. Vol. 15(4): 227-283.

Pickle Williams Linda \& Su Yuchen. (2002). Within-state geographic patterns of health insurance coverage and health risk factors in the United States. American Journal of Preventive Medicine. Volume 22, Issue 2, Pages 75-83.

Rohaya Mohd-Nor, Teddy Edwin Chapun \& Constance Rinen Justin Wah. (2013). Malaysian rural community as consumer of health information and their use of ICT. Malaysian Journal of Communication. Vol 29 (1): 1-27.

Sorensen. K, Van Den Broucke. S, Brand. H, Fullam. J, Doyle. G, Pelikan J. \& Slonszka Z. (2012). Health literacy and public health: a systematic review and integration of definitions and models. BMC Public Health, (1), 80.

Sui Daniel Z. \& Holt James B. (2008). Visualizing and analysing publichealth data using value-by-area cartograms: Toward a new synthetic framework. Cartographica Journal, Vol. 43, Issue 1, pp. 3-20.

Cox, A., Marchington, M., \& Suter, J. (2009). Employee involvement and participation: developing the concept of institutional embeddedness using WERS2004. The International Journal of Human Resource Management, 20(10), 2150-2168.

Gollan, P. and Lewin, D. (2013). Employee representation in non-union firms: An overview. Journal of Industrial Relations, Vol. 52, No. S. 1. Wiley Periodical Inc.

\section{Book}

Burrough P.A \& McDonnell R.A. (1998). Creating continuous surfaces from point data. Principles of geographic information systems. Oxford, United Kingdom. Oxford University Press. 
McDonnell, R \& Kemp, K. (1995). International GIS dictionary. John Wiley $\&$ Sons, Inc, United Kingdom.

Rushton G, Armstrong M.P, Gittler J, Greene B.R, Paulik C.E, West M.M. (2008). Geocoding health data: The use of geographic codes in cancer prevention and control, research and practice. Boca Raton, FL: CRC Press.

\section{Internet source}

Cromley Ellen, K. (2003). GIS and disease. Annual Review of Public Health. Vol. 24:7-24. University of Connecticut, USA: Rev Public Health. Retrieved from https://www.annurev.publhealth.

Institute for Public Health 2015. National Health and Morbidity Survey 2015. Non-communicable diseases, risk factors and other health problems. Vol. II. Public Health, National Institute for Health. Ministry of Health: Kuala Lumpur. Retrieved from https://www.moh.gov.my.

Nicole Lurie, Laurie T. Martin, Teague Ruder, Jose J. Escarce, Bonnie Ghosh-Dastidar, Dan Sherman, Chloe E. Bird \& Allen Freemont. (2009). Estimating and mapping health literacy in the state of Missouri. Santa Monica, CA: RAND Corporation. Retrieved from http://www.rand.org.pubs/working_papers/WR735.html.

Nutbeam, D. Tang, K.C. \& Smith, B.J. (2006). World Health Organization Health Promotion Glossary: New Terms, Health Promotion International Advance Retrieved from http://www.who.int/healthpromotion/

Sabah Economic Development and Invesment Authority (SEDIA). (2007). Sabah Development Corridor Blueprint 2008-2025. Institute for Development Studies (IDS): Kota Kinabalu. Retrieved from http://www.sedia.com.my/SDC_Blueprint/

Takashi Yamashita \& J. Scott Brown. (2012). An exploratory analysis of American adults' health literacy at county-level. Miami University, Oxford,USA. Retrieved from https://paa2012.princeton.edu/papers/

Utusan Borneo. (2018). Tibi kekal masalah kesihatan utama di Sabah. Retrieved from https://www.utusanborneo.com/

World Health Organization (WHO). (1998). Health Promotion Glossary. WHO:Geneva. Retrieved from http://www.who.int/health promotion/

\section{Conference Proceeding}

Jasmin Arif Shah \& Siti Raba'ah Hamzah. (2016). Developing a conceptual model of youth health literacy in Malaysia. In: International 
Journal of Borneo Social Transformation Studies (JOBSTS), Vol. 6, Number 1, 2020

ISSN 2462-2095

Universiti Malaysia Sabah

Conference on Youth 2016, 15-17 Nov. Mines Wellness Hotel, Seri Kembangan, Selangor. 